\title{
Associative learning and discrimination of 10 plant species by the egg-larval parasitoid, Ascogaster reticulata Watanabe (Hymenoptera: Braconidae)
}

\author{
Hiroyuki SEINO and Yooichi KAINOH*
}

Laboratory of Applied Entomology and Zoology, Graduate School of Life and Environmental Sciences, University of Tsukuba; Ibaraki 305-8572, Japan

(Received 20 April 2007; Accepted 10 September 2007)

\begin{abstract}
The effects of associative learning of plant chemicals on host-searching behavior in Ascogaster reticulata Watanabe, an egg-larval parasitoid of the smaller tea tortrix, Adoxophyes honmai Yasuda, were investigated. Learned responses of conditioned and non-conditioned plant species were examined by a two-choice assay. Before the two-choice assays, females were given a rewarding oviposition experience or unrewarding experience on a leaf disc or leaf extract of either tea, camellia, sasanqua, bayberry, chinquapin, rose, Japanese cedar, fern pine, mulberry and corn. Following the experience, females were tested in a choice test between tea leaf and an alternative plant leaf. The results of the twochoice assays with leaf square discs were similar to tests using leaf extracts. Females that were conditioned with tea leaf showed a significant preference for tea leaf over the alternative plant species, except for leaves of the genus Camellia (camellia and sasanqua). Wasps conditioned with the other nine plant leaves only showed a significant preference for bayberry, mulberry, fern pine and corn. Females that had rewarding and unrewarding experiences were able to distinguish between tea and camellia. These results suggest that $A$. reticulata females are able to distinguish different plant species except for closely related species and some plant species; however, combinations with rewarding and unrewarding experiences enabled females to discriminate closely related species.
\end{abstract}

Key words: Host-searching behavior; unrewarding experience; plant chemicals

\section{INTRODUCTION}

The smaller tea tortrix Adoxophyes honmai Yasuda is a major tea pest in Japan (Minamikawa and Osakabe, 1979). Ascogaster reticulata Watanabe is a solitary egg-larval endoparasitoid of $A$. honmai and seven other tortricid species (Watanabe, 1967; Kamijo, 1973; Takagi, 1974; Kawakami and Kainoh, 1986). During host searching and attack, A. reticulata females use several host kairomones, e.g. wing scales and adult host excretion (Kainoh and Tamaki, 1982; Kainoh et al., 1982, 1990). Furthermore, $A$. reticulata females are able to learn to associate plant contact chemicals with the host egg mass as host-searching cues (Kainoh, 1997; Honda et al., 1998), and the learning of plant cues contributes to efficient host-searching behavior. Plant exploitation by polyphagous hosts such as $A$. honmai is spatially and temporally variable, and asso- ciative learning of plant cues provides flexibility to adapt to changes in plants (Vet, 2001).

Experienced females showed zigzag walking while exhibiting antennating responses at an almost constant speed along a line treated with a tea leaf extract. Previous studies (Kainoh, 1997; Honda et al., 1998) showed that the female response to plant chemicals is highest after females have three subsequent rewarding experiences with at least 5 min between each reward. In addition, female learning ability depends on the presence of mature eggs in the ovary because newly emerged females lacking mature eggs in their ovaries showed a lower response to learned plant contact chemicals than older females (Honda and Kainoh, 1998).

The ability to discriminate between conditioned and non-conditioned plant species is important for parasitoid searching behavior. Many studies have

\footnotetext{
* To whom correspondence should be addressed at: E-mail: parasite@sakura.cc.tsukuba.ac.jp DOI: $10.1303 / \mathrm{aez} .2008 .83$
} 
reported that parasitoids are able to discriminate between plants based on previous experiences (Kaas et al., 1990; Turlings et al., 1990; McAuslane et al., 1991a; McCall et al., 1993). These studies typically examined responses to two plant species (two hosts or host and nonhost); however, parasitoids must discriminate between previously learned plant species and many other plant species in the host habitat location, although to what extent $A$. reticulata females can distinguish conditioned plants and other plants has not yet been investigated and relatively few studies have examined the effects of conditioning on responses to a wider range of plants (Kester and Barbosa, 1992).

In this study, we conducted a two-choice (tea and one of another nine plants) bioassay with $A$. reticulata to investigate its ability to discriminate plant species through associative learning. The plants used in this assay were tea (Camellia sinensis variety "Yabukita") and nine other plant species, camellia (Camellia japonica), sasanqua (Camellia sasanqua), bayberry (Myrica rubra), chinquapin (Castanopsis cuspidata var. sieboldii), rose (Rosa hybrida), Japanese cedar (Cryptomeria japonica), fern pine (Podocarpus macrophyllus), mulberry (Morus bombycis) and corn (Zea mays variety "Peter 610"). Except for mulberry and corn, all other species are known as host plants of A. honmai (Minamikawa and Osakabe, 1979).

Conditioning as well as the assay was conducted using ethanol extracts to standardize the physical state and surface area of each plant. In addition, two-choice bioassays using leaf discs of tea, camellia and corn were conducted to confirm whether the results of the leaf extracts reflect female behavior on a real leaf.

\section{MATERIALS AND METHODS}

Insect rearing. Colonies of $A$. reticulata and its host $A$. honmai were obtained from a stock culture at the University of Tsukuba. The rearing of $A$. reticulata was based on the methods described by Kainoh (1988), and that of A. honmai on Tamaki (1966). Parasitized and unparasitized A. honmai larvae were reared on an artificial diet containing tea leaf powder. A. reticulata cocoons and A. honmai pupae were taken out of the rearing containers and each $A$. reticulata cocoon was separately placed into a $5 \mathrm{ml}$ sample tube until they emerged.
Emerged adult wasps were sexed and 10 to 20 of each were kept in a plastic container $(15 \mathrm{~cm}$ diam., $9 \mathrm{~cm}$ high) with wet cotton on the bottom and honey on the walls. Rearing and experiments were conducted in the laboratory at $25 \pm 1^{\circ} \mathrm{C}$ and $60 \pm 10 \% \mathrm{RH}$ under a $16 \mathrm{~L}-8 \mathrm{D}$ photoperiod. Threeto four-day-old unmated female wasps with no oviposition experience and 1-day-old host egg masses were used in all experiments.

Plant leaves. Leaves of potted tea plants, and corn were used. Camellia leaves were collected on the campus of the University of Tsukuba. All leaves for conditioning and bioassays were cut to uniform size $(2 \mathrm{~cm} \times 3 \mathrm{~cm}$ square) .

Plant extracts. Leaves of tea plant, mulberry and corn were obtained from our greenhouse. Leaves of camellia, sasanqua, bayberry, chinquapin, rose, fern pine and Japanese cedar were collected in the University of Tsukuba. Five grams of the leaves were soaked in $50 \mathrm{ml}$ ethanol for $24 \mathrm{~h}$. The extract was filtered and stored at $5^{\circ} \mathrm{C}$ until use.

\section{Discrimination of plant leaves}

Conditioning. A leaf square $(2 \mathrm{~cm} \times 3 \mathrm{~cm})$ of each plant was placed at the center of a $9 \mathrm{~cm}$ glass Petri dish. A host egg mass was placed in the center of the leaf and a 3- to 4-day-old female parasitoid was released into the covered dish. The female was allowed to oviposit in the host egg mass for $2 \mathrm{~min}$, and was then gently removed with an insect aspirator and placed in a container $(15 \mathrm{~cm}$ in diam., $9 \mathrm{~cm}$ high) with wet cotton on the bottom and honey on the walls before being used in the next conditioning or the bioassay of learned responses. Conditioning was repeated three times on the same leaf square at 30-60 min intervals and the females were tested in a two-choice bioassay 30-60 min after the last conditioning.

Bioassay. One of the two combinations of leaves: 1) one tea leaf square and one camellia leaf square, and 2) one tea leaf square and one corn leaf square, was placed on the bottom of a $9 \mathrm{~cm}$ Petri dish. A. reticulata females conditioned with tea were individually released into the dishes containing either combination of leaves. Females conditioned with camellia were individually released into the dish containing tea and camellia leaves. Corn-conditioned females were individually released into the dish containing tea and corn leaves. Their behavior was observed for $3 \mathrm{~min}$. The total time spent on each leaf was measured with a stop- 
watch. Ten females were used for each conditioning group.

\section{Discrimination of plant extracts}

Conditioning. Plant extracts $(5 \mu \mathrm{l})$ were applied to a $9 \mathrm{~cm}$ line across the center of the $9 \mathrm{~cm}$ glass Petri dish. After the solvent was evaporated by air drying, a host egg mass was placed in the center and 3- to 4-day-old female parasitoids were released into the dish. The females were conditioned by the same method as in the bioassay of plant leaves ( 2 min oviposition, three subsequent conditioning trials).

Bioassay. The tea leaf extract $(5 \mu \mathrm{l})$ and one of the nine alternative plant leaf extracts were applied crosswise on the bottom of a $9 \mathrm{~cm}$ Petri dish. The extracts were not applied in the center area $(1 \mathrm{~cm}$ in diam.) to prevent the mixing of lines. After the solvent evaporated, a female was released into the dish and her behavior was observed for $3 \mathrm{~min}$. The total distance of zigzag walking along each extracttreated line was measured with a scale on the bottom of the Petri dish. The preference rate was calculated based on the following equation:

$$
\text { Preference rate }(\%)=\frac{\mathrm{WT} \text { or } \mathrm{WA}}{\mathrm{WT}+\mathrm{WA}} \times 100
$$

Where, WT is the walking distance on the tea leaf extract line and WA is the walking distance on the alternative leaf extract line.

Ten to 15 females were used for each extract combination.

\section{Effect of rewarding and unrewarding experi-} ence

Conditioning. Petri dishes were prepared with 9 $\mathrm{cm}$ lines of tea, camellia or corn extracts, as described above. Females were conditioned by allowing them to oviposit in the host egg mass on the tea leaf extract for $2 \mathrm{~min}$ as a rewarding experience (tea ${ }^{+}$experience). The unrewarding experience consisted of females being exposed to camellia or corn extracts with no host egg mass for $5 \mathrm{~min}$ (camellia ${ }^{-} / \mathrm{corn}^{-}$experience). Rewarding and unrewarding experiences were repeated three times alternately at $15 \mathrm{~min}$ intervals.

Bioassay. Each conditioned female was released into a Petri dish in which one of the two combinations of extracts: 1) tea and camellia, and 2) tea and corn, was applied, and female behavior was observed for $3 \mathrm{~min}$. The preference rate was calcu- lated based on the distance walked along each of the extract-treated lines. Ten to 15 females were used for each group.

\section{RESULTS}

\section{Discrimination of plant leaves}

The total searching time of tea leaf-conditioned females on tea and camellia leaves was not significantly different (tea: $11.02 \mathrm{~s}$, camellia: $11.47 \mathrm{~s}$ ) (paired $t$-test, $p=0.867$ ) (Fig. 1A). Also, the searching time of camellia-leaf-conditioned females was not significantly different (tea: $8.67 \mathrm{~s}$, camellia: $11.70 \mathrm{~s}$ ) (paired $t$-test, $p=0.197$ ) (Fig. 1A). In contrast, in the case of a choice between tea and corn leaves, females significantly preferred the leaf on which they had been conditioned (tea leaf-conditioned females: tea: $17.41 \mathrm{~s}$, corn: $2.93 \mathrm{~s}$ ) (paired $t$-test, $p=0.006$ ) (corn leaf-conditioned females: tea: $6.39 \mathrm{~s}$, corn: $10.71 \mathrm{~s}$ ) (paired $t$-test, $p=0.029)$ (Fig. 1B).

A)

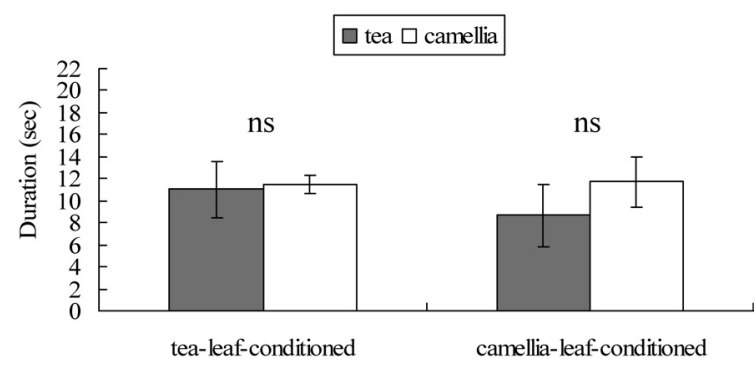

B)

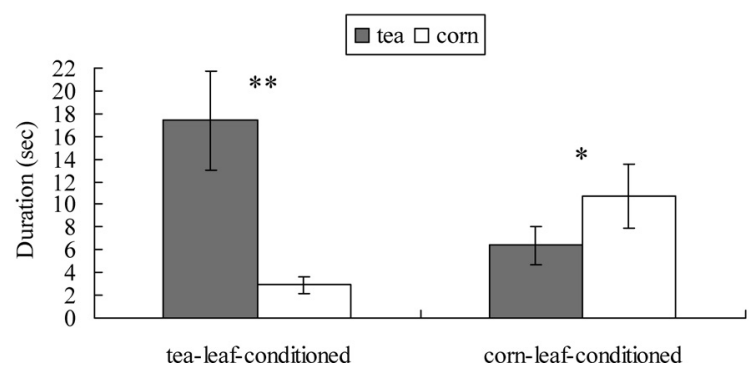

Fig. 1. Responses of $A$. reticulata females conditioned with tea or camellia leaf (A) $(n=10)$ and tea or corn leaf (B) $(n=10)$. Bars indicate the duration of searching by test females on tea, camellia and corn leaf (mean \pm SE). 'ns' indicates no significant difference in each searching period (paired $t$-test, $p>0.05)$. Asterisks indicate a significant difference within each group (paired $t$-test, $* p<0.05,{ }^{* *} p<0.01$ ). 
A)

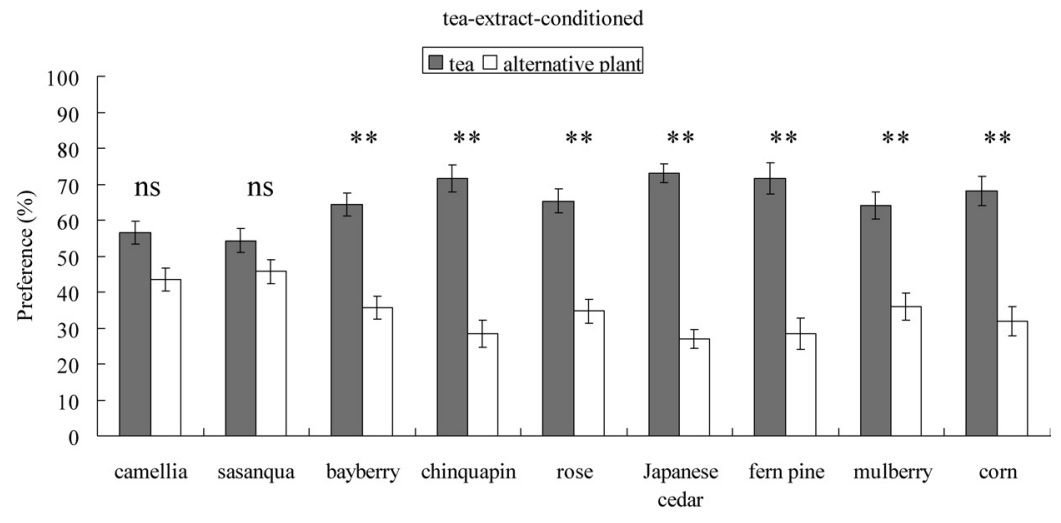

B)

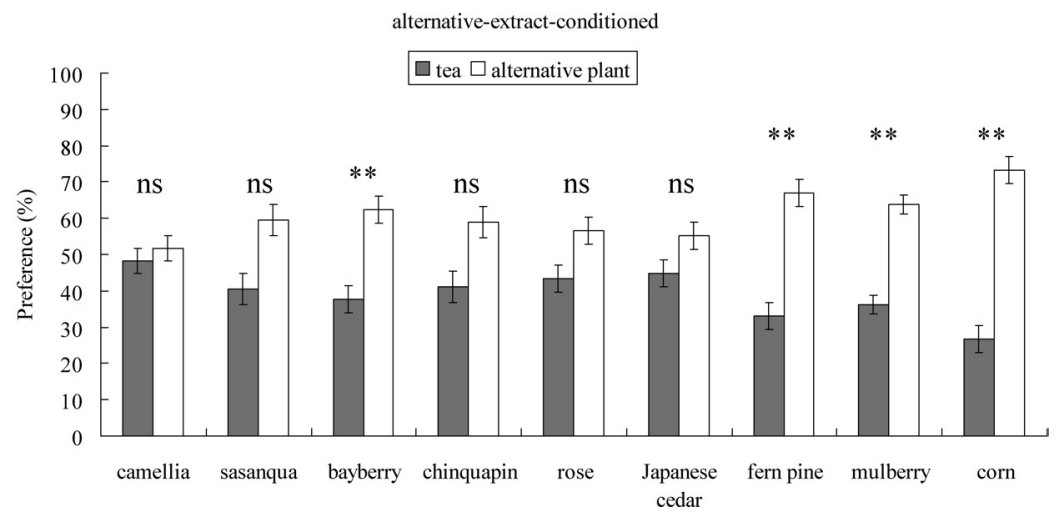

Fig. 2. Responses of $A$. reticulata females conditioned with tea leaf extracts (A) $(n=10-15)$ and nine other plant leaf extracts (B) $(n=10-15)$. Bars indicate the percentage of walking distance on tea and alternative plant extracts (mean \pm SE). 'ns' indicates no significant difference in each test group (paired $t$-test, $p>0.05$ ). Asterisks indicate a significant difference in each test group (paired $t$-test, $* * p<0.01)$.

\section{Discrimination of plant extracts}

The tea extract-conditioned females preferred the tea leaf extract; however, tea versus camellia or sasanqua showed no significant differences (tea: $56.6 \%$, camellia: $43.4 \%$; $p=0.059$, paired $t$-test) (tea: $54.3 \%$, sasanqua: $45.7 \% ; p=0.240$, paired $t$ test) (Fig. 2A). Females conditioned with bayberry, fern pine, mulberry and corn leaf extracts showed a significant preference for the plant extract (bayberry: $62.3 \%, p=0.005$; fern pine: $67.0 \%$, $p=0.0004$; mulberry: $63.8 \%, p=0.0006$; corn: $73.3 \%, p=0.0002$, paired $t$-test) on which they had been conditioned (Fig. 2B). On the other hand, camellia, sasanqua, rose, chinquapin and Japanese cedar extract-conditioned females did not show a significant preference for the plant extract on which they had been conditioned (camellia: 51.7\%, $p=0.619$; sasanqua: $59.5 \%, p=0.053$; rose: $56.6 \%$, $p=0.114$; chinquapin: $58.9 \%, p=0.061$; Japanese cedar: $55.2 \%, p=0.210$, paired $t$-test) (Fig. 2B).

\section{Effect of rewarding and unrewarding experi- ences}

The tea ${ }^{+}$- and camellia ${ }^{-}$-experienced females showed increased responses to the tea extract (tea: $66.0 \%, p=0.0003$, paired $t$-test) when compared to the only tea ${ }^{+}$-experienced females (tea: $56.6 \%$, $p=0.059$, paired $t$-test) (Figs. $2 \mathrm{~A}$ and $3 \mathrm{~A}$ ). The tea ${ }^{+}$- and corn $^{-}$-experienced females did not show any differences in the responses to the tea extract $\left(\right.$ tea $^{+}:$: $68.1 \%, p=0.0019 ;$ tea $^{+} /$corn $^{-}: 70.4 \%, p=$ 0.00005 , paired $t$-test) (Figs. 2A and 3B). The total walking distance on tea and camellia (tea $^{+}$: $12.60 \mathrm{~cm}$, tea $^{+} /$camellia $^{-}: 14.07 \mathrm{~cm}$ ) or that on tea 
A)

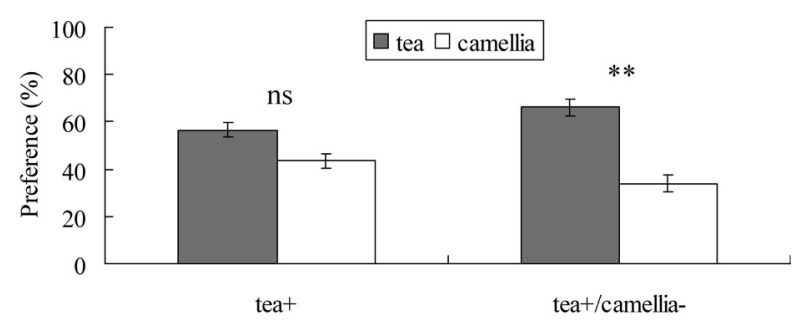

B)

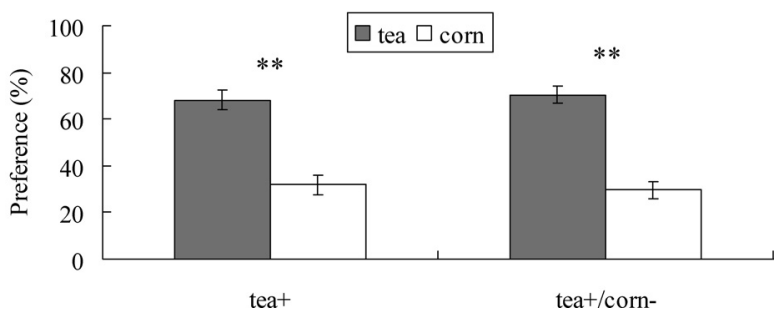

Fig. 3. Responses of tea rewarding-experienced A. reticulata females $\left(\right.$ tea $\left.^{+}\right)$, tea rewarding-/camellia unrewarding-experienced females (tea ${ }^{+} /$camellia $^{-}$) (A) and tea ${ }^{+}$, tea $^{+} / \mathrm{corn}^{-}$ females (B) $(n=10-15)$. Bars indicate the percentage of walking distance on tea and camellia or corn plant extracts (mean $\pm \mathrm{SE}$ ). ' $\mathrm{ns}$ ' indicates no significant difference in each test group (paired $t$-test, $p>0.05$ ). Asterisks indicate a significant difference in each test group (paired $t$-test, $* * p<0.01$ ).

and corn $\left(\right.$ tea $^{+}: 11.4 \mathrm{~cm}$, tea $\left.^{+} / \mathrm{corn}^{-}: 12.4 \mathrm{~cm}\right)$ extracted lines was not significantly different $(p>0.05$, paired $t$-test).

\section{DISCUSSION}

In general, $A$. reticulata females tend to search for plant species on which they have had a previous rewarding experience. Even though mulberry and corn are non-host plants of $A$. honmai, A. reticulata was able to learn these plants (Fig. 2A, B). Other parasitoids have also been reported to learn novel host plants (Kester and Barbosa, 1991, 1992; McAuslane et al., 1991a) or even volatiles not related to natural ecosystems (e.g., Olson et al., 2003). The majority of these parasitoids, including $A$. reticulata, are polyphagous. $A$. honmai feeds on more than 90 species of plants from 44 families, including herbs, broadleaf trees and conifers (Minamikawa and Osakabe, 1979). Since it is difficult to innately respond to such a broad range of plant species, the associative learning of rewarding plant odors is especially adaptive for parasitoids such as A. reticulata.

Tea extract-conditioned and camellia or sasanqua extract-conditioned females did not discriminate between tea and camellia or sasanqua (Fig. 2A, B). Tea, camellia and sasanqua are categorized into the same genus, Camellia. A. reticulata seems to have difficulty in distinguishing between these closely related plant species. Microplitis croceipes (Cresson) (Braconidae) is able to discriminate between related chemicals based on the carbon chain length position and type of functional group (Meiners et al., 2002); however, M. croceipes conditioned with a mixture of methyl jasmonate, $\beta$ caryophyllene and 2-octanone compounds had difficulty discriminating between a mixture of these three compounds and a binary mixture of methyl jasmonate and $\beta$-caryophyllene compounds (Meiners et al., 2003). A similar phenomenon was reported in the European honeybee, Apis mellifera L. (Blight et al., 1997) in which $83 \%$ of honeybees conditioned to oilseed rape, Brassica napus, flower extract showed conditioned proboscis extension responses to a mixture of eight compounds from oilseed rape flower volatiles ( $\alpha$-pinene, phenylacetaldehyde, $\beta$-ocimene, $\alpha$-terpinene, linalool, 2phenylethanol, $(E, E)$ - $\beta$-farnesene and 3 -carene). In addition, $85 \%$ of the bees conditioned to these 8 compounds responded to a mixture of the 3 most active compounds, phenylacetaldehyde, linalool and $(E, E)-\beta$-farnesene. Laloi et al. (2000) also reported that honeybees conditioned to a blend of nine oilseed rape volatiles established a hierarchy among the components. Honeybees seem to establish responses to several key compounds of total plant volatiles, namely phenylacetaldehyde, linalool and $(E, E)-\beta$-farnesene in oilseed rape, when they experience the full blend. We speculate that $A$. reticulata similarly learn key compounds when they experience a plant extract. A. reticulata females were unable to discriminate between tea and camellia or tea and sasanqua, indicating the compounds that account for a major part of learning are common to all three species.

$\mathrm{Tea}^{+}$- and camellia ${ }^{-}$-experienced females were able to discriminate between tea and camellia (Fig. $3 \mathrm{~A}$ ), suggesting that they can detect minor components during the learning process when sufficiently challenged. Similar results were reported in Leptopilina heterotoma (Vet et al., 1998). L. hetero- 
toma did not discriminate between odors from two apple varieties when they received only a rewarding experience; however, when they received both rewarding and unrewarding experiences, L. heterotoma discriminated between apple varieties. After an unrewarding experience, parasitoid species reduced their response to the associated chemical cues (Papaj et al., 1994; Iizuka and Takasu, 1998). Unrewarding experiences lead $A$. reticulata females to quickly reduce their learned response (Honda et al., 1999). Tea extract-conditioned females fully responded by walking along the line treated with tea extract; however, the walking distance significantly decreased the next day compared to females that did not experience an unrewarding trial. Moreover, the present study showed that unrewarding experiences enhance the discrimination ability of reward-experienced females (Fig. 3A).

Females conditioned to rose, chinquapin and Japanese cedar were unable to discriminate between tea and these plants (Fig. 2B). A. reticulata did not learn these plants even though rose, chinquapin and Japanese cedar are host plants of $A$. honmai. These plants may contain some chemicals that inhibit responses to plant extracts, reduce learning motivation or blocking associative learning.

Most $A$. reticulata females showed some level of response to non-conditioned species of plant leaves or extracts (i.e., Fig. 2). In addition, the responses of tea ${ }^{+} /$corn $^{-}$-experienced females to corn extracts (average $3.47 \mathrm{~cm}: n=15$ ) did not decrease, as was seen in only tea ${ }^{+}$-experienced females (average $3.8 \mathrm{~cm}: n=10)$ (Fig. 3B). These responses to nonconditioned plants are thought to be caused by females becoming more sensitive. Oviposition on or contact with host-derived kairomones appears to result in a general increase in a parasitoid's response to various stimuli. This phenomenon is called "sensitization" (Turlings et al., 1989; McAuslane et al., 1991b; Eller et al., 1992; Takasu and Lewis, 2003). Inexperienced $A$. reticulata females do not respond to plant chemicals but after an oviposition experience (absence of plant chemicals), they respond to these plant chemicals (Honda et al., 1998).

Results from the bioassay of leaves and leaf extracts suggest that $A$. reticulata can learn and discriminate between plant species based on contact chemicals in the leaves; however, residence time on corn leaves was rather low (Fig. 1B). Corn leaves are more hirsute than tea and $A$. reticulata behavior seemed to be impaired by these hairs. Trichomes or secretions from glandular trichomes on the plant surface sometimes interfere with insect behavior. Parasitic wasps have also been shown to be affected by hairy structures or repelled by glandular trichome volatiles (van Lenteren et al., 1995; Sutterlin and van Lenteren, 1997; Romeis et al., 1998; Al-wahaibi and Walker, 2000; Lovinger et al., 2000). Trichomes and similar plant structures are likely to have negative impacts on host-searching behavior of $A$. reticulata, and so can be expected to affect the preference for and discrimination of plant species.

Based on these results, we propose the following hypothesis of how learning plant chemicals and unrewarding experiences affect host-searching behavior of $A$. reticulata in the field. Female parasitoids learn the key components of each plant species when they oviposit in a host egg mass; however, this reward by itself is insufficient for females to discriminate between closely related plant species. This lack of discrimination may also represent an adaptive response because when tea is infested with A. honmai, plants of the genus Camellia very likely contain host egg masses. Similarly, hostsearching behavior on plants that do not have host egg masses constitutes an unrewarding experience. In response to such an unrewarding experience, females reduce their searching response and gradually give up searching on those plants; however, camellia $^{-}$experience did not reduce the response to tea (Fig. 3A). This suggests that minor compounds may affect the unrewarding experience in this species. After unrewarding experiences, $A$. reticulata females show an increased tendency to search for new host eggs on other plant species based on a sensitized response.

How each component in plant extracts affects $A$. reticulata and how females learn and discriminate other cues (visual or volatile) is the subject of future research.

\section{ACKNOWLEDGEMENTS}

We are indebted to Prof. F. L. Wäckers and Dr. DeMar Taylor for helpful comments on the manuscript, and Prof. H. Honda for encouragement during this study. This work was supported in part by Grants-in-Aid for Scientific Research from the Ministry of Education, Culture, Sports, Science and 
Technology of Japan (No. 17658025 to Y.K.).

\section{REFERENCES}

Al-wahaibi, A. K. and G. P. Walker (2000) Searching and oviposition behavior of a mymarid egg parasitoid, Anagrus nigriventris, on five host plant species of its leafhopper host, Circulifer tenellus. Entomol. Exp. Appl. 96: 9-25.

Blight, M. M., M. L. Metayer, M. P. Delegue, J. A. Pickett, F. Marion-Poll and L. J. Wadham (1997) Identification of floral volatiles involved in recognition of oilseed rape flowers, Brassia napus by honeybees, Apis mellifera. J. Chem. Ecol. 23: 1715-1727.

Eller, F. J., J. H. Tumlinson and W. J. Lewis (1992) Effect of host diet and preflight experience on the flight responses of Microplitis croceipes (Cresson). Physiol. Entomol. 17: 235-240.

Honda, T. and Y. Kainoh (1998) Age-related fecundity and learning ability of the egg-larval parasitoid, Ascogaster reticulatus Watanabe (Hymenoptera: Braconidae). Biol. Cont. 13: 177-181.

Honda, T., Y. Kainoh and H. Honda (1998) Enhancement of learned response to plant chemicals by the egg-larval parasitoid, Ascogaster reticulatus Watanabe (Hymenoptera: Braconidae). Appl. Entomol. Zool. 33: 271-276.

Honda, T., Y. Kainoh and H. Honda (1999) The persistence of a learned response in the egg-larval parasitoid Ascogaster reticulatus Watanabe (Hymenoptera: Braconidae). Entomol. Sci. 2: 335-340.

Iizuka, T. and K. Takasu (1998) Olfactory associative learning of the pupal parasitoid Pimpla luctuosa Smith (Hymenoptera: Ichneumonidae). J. Insect Behav. 11: 743760.

Kaas, J. P., G. W. Elzen and S. B. Ramaswamy (1990) Learning in Microplitis croceipes Cresson (Hym., Braconidae). J. Appl. Entomol. 109: 268-273.

Kainoh, Y. (1988) Some factors influencing sex ratio in Ascogaster reticulatus Watanabe (Hymenoptera: Braconidae). Appl. Entomol. Zool. 23: 35-40.

Kainoh, Y. (1997) Learning of plant's contact chemicals by the egg-larval parasitoid, Ascogaster reticulatus Watanabe (Hymenoptera: Braconidae). Appl. Entomol. Zool. 32: 416-418.

Kainoh, Y. and Y. Tamaki (1982) Searching behavior and oviposition of the egg-larval parasitoid, Ascogaster reticulatus Watanabe (Hymenoptera: Braconidae). Appl. Entomol. Zool. 17: 194-206.

Kainoh, Y., T. Hiyori and Y. Tamaki (1982) Kairomone of the egg-larval parasitoid, Ascogaster reticulatus Watanabe (Hymenoptera: Braconidae). Appl. Entomol. Zool. 17: $102-110$.

Kainoh, Y., S. Tatsuki and T. Kusano (1990) Host moth scales; a cue for host location for Ascogaster reticulatus Watanabe (Hymenoptera: Braconidae). Appl. Entomol. Zool. 25: 17-25.

Kamijo, K. (1973) The parasite complex of Choristoneura diversana Hübner injurious to todo-fir, Abies sachalinensis Masters. Jpn. J. Appl. Entomol. Zool. 20: 380-386 (in Japanese).
Kawakami, T. and Y. Kainoh (1986) Host specificity of the egg-larval parasitoid, Ascogaster reticulatus Watanabe (Hymenoptera: Braconidae) among five tortricid and one noctuid species. Appl. Entomol. Zool. 21: 8-14.

Kester, K. M. and P. Barbosa (1991) Behavioral and ecological constrains imposed by plants on insect parasitoids: implications for biological control. Biol. Cont. 1: 94 106.

Kester, K. M. and P. Barbosa (1992) Effects of postemergence experience on searching and landing responses of the insect parasitoid, Cotesia congregata (Say) (Hymenoptera: Braconidae), to plants. J. Insect Behav. 3: 471-490.

Laloi, D., O. Bailez, M. M. Blight, B. Roger, M. PhamDelegue and L. J. Wadhams (2000) Recognition of complex odors by restrained and free-flying honeybees, Apis mellifera. J. Chem. Ecol. 26: 2307-2319.

Lovinger, A., D. Liewehr and W. O. Lamp (2000) Glandular trichomes on alfalfa impede searching behavior of the potato leafhopper parasitoid. Biol. Cont. 18: 187-192.

McAuslane, H. J., S. B. Vinson and H. J. Williams (1991a) Influence of adult experience on host microhabitat location by generalist parasitoid, Campoletis sonorensis (Hymenoptera: Ichneumonidae). J. Insect Behav. 4: 101113.

McAuslane, H. J., S. B. Vinson and H. J. Williams (1991b) Stimuli influencing host microhabitat location in the parasitoid Campoletis sonorensis. Entomol. Exp. Appl. 58: 267-277.

McCall, P. J., T. C. J. Turlings, W. J. Lewis and J. H. Tumlinson (1993) Role of plant volatiles in host location by the specialist parasitoid Microplitis croceipes Cresson (Braconidae: Hymenoptera). J. Insect Behav. 6: 625-639.

Meiners, T., F. Wäckers and W. J. Lewis (2002) The effect of molecular structure on olfactory discrimination by the parasitoid Microplitis croceipes. Chem. Senses 27: 811-816.

Meiners, T., F. Wäckers and W. J. Lewis (2003) Associative learning of complex odours in parasitoid host location. Chem. Senses 28: 231-236.

Minamikawa, J. and M. Osakabe (1979) Insect Pest of the Tea Plant. Japan Plant Protection Association, Tokyo. 322 pp. (in Japanese).

Olson, D. M., G. C. Rains, T. Meiners, K. Takasu, M. Tertuliano, J. H. Tumlinson, F. L. Wäckers and W. J. Lewis (2003) Parasitic wasps learn and report diverse chemicals with unique conditionable behaviors. Chem. Senses 28: 545-549.

Papaj, D. R., H. Snellen, K. Swaans and L. E. M. Vet (1994) Unrewarding experiences and their effect on foraging in the parasitic wasp Leptopilina heterotoma (Hymenoptera: Eucoilidae). J. Insect Behav. 7: 465-481.

Romeis, J., T. G. Shanower and C. P. W. Zebitz (1998) Physical and chemical plant characters inhibiting the searching behaviour of Trichogramma chilonis. Entomol. Exp. Appl. 87: 275-284.

Sutterlin, S. and J. C. van Lenteren (1997) Influence of hairiness of Gerbera jamesonii leaves on the searching efficiency of the parasitoid Encarsia formosa. Biol. Cont. 
9: $157-165$.

Takagi, K. (1974) Monitoring of hymenopterous parasite in the field. Bull. Nat. Res. Inst. Tea 10: 91-131 (in Japanese with English summary).

Takasu, K. and W. J. Lewis (2003) Learning of host searching cues by the larval parasitoid Microplitis croceipes. Entomol. Exp. Appl. 108: 77-86.

Tamaki, Y. (1966) Mass rearing of the smaller tea tortrix, Adoxophyes orana Fischer von Röslerstamm, on a simplified artificial diet for successive generations (Lepidoptera: Torticidae). Appl. Entomol. Zool. 1: 120-124.

Turlings, T. C. J., J. H. Tumlinson, W. J. Lewis and L. E. M. Vet (1989) Beneficial arthropod behavior mediated by airborne semiochemicals. VIII. Learning of host-related odors induced by a brief contact experience with host byproducts in Cotesia marginiventris (Cresson), a generalist larval parasitoid. J. Insect Behav. 2: 217-225.

Turlings, T. C. J., J. W. A. Scheepmaker, L. E. M. Vet, J. H. Tumlinson and W. J. Lewis (1990) How contact foraging experience affect preference for host-related odors in the larval parasitoid Cotesia marginiventris (Cresson) (Hymenoptera: Braconidae). J. Chem. Ecol. 16: 15771589.

van Lenteren, J. C., Z. H. Li, J. W. Kamerman and R. Xu (1995) The parasite-host relationship between Encarsia formosa (Hym., Aphelinidae) and Trialeurodes vaporariorum (Hom., Aleyrodidae) XXVI. Leaf hairs reduce the capacity of Encarsia to control greenhouse whitefly on cucumber. J. Appl. Entomol. 119: 553-559.

Vet, L. E. M. (2001) Parasitoid searching efficiency links behavior to population process. Appl. Entomol. Zool. 36: 399-408.

Vet, L. E. M., A. G. De Jong, E. Franchi and D. R. Papaj (1998) The effect of complete versus incomplete information on odour discrimination in a parasitic wasp. Anim. Behav. 55: 1271-1279.

Watanabe, C. (1967) Description of a new species of the genus Ascogaster Wesmael and notes on synonymy of Apanteles species (Hymenoptera, Braconidae). Insecta Matsumurana 29: 41-44. 